LICENÇA CC BY:

Artigo distribuído sob os termos

Creative Commons, permite uso e distribuição irrestrita em qualquer meio desde que o autor credite a fonte original.

\section{A INERÊNCIA DO PERFORMAR ARTISTA, DOCENTE E PESQUISADOR(A) PARA ALÉM DE BARRAS E HIFENS}

THE INHERENCE OF THE PERFORMING ARTIST, TEACHER AND RESEARCHER BEYOND BACKSLASHES AND HYPHENS LA INHERENCIA DEL ARTISTA, EL PROFESOR Y EL INVESTIGADOR(A) MÁS ALLÁ DE LAS BARRAS Y GUIONES

Michelle Bocchi Gonçalves ${ }^{1}$

Jair Mario Gabardo Junior ${ }^{1}$

'Programa de Pós-Graduação em Educação da Universidade Federal do

Paraná, Curitiba, PR, Brasil.

Artigo recebido em: 31/03/2020

Aprovado em: 25/11/2020

Resumo: Vinculados ao grupo de pesquisa Laboratório de Estudos em Educação Performativa, Linguagem e Teatralidades (ELiTe/UFPR/CNPq), buscamos, por meio deste artigo, alavancar considerações a respeito da inerência das performances dos papéis sociais do artista, docente e pesquisador(a) em dramas sociais escolares. Isto significa, pois, olhar atentamente para os modos como essas performances se concebem nas particularidades das suas manifestações prática e teórica, em diferentes estudos pela via das grafias, nas quais elas se distinguem. O recorrente uso dos sinais gráficos de barra oblíqua (/) e hífen (-) para delimitar aquilo que operamos por entre o fazer artístico, assim como os contextos do ensino da arte, e o ofício da pesquisa, fornecem subsídios para que, nas considerações aqui desenvolvidas, possamos problematizar o endosso daquelas variáveis ( -) na expressão escrita. O marco de nossa proposição investigativa são recortes pontuais dos Estudos da Performance e seus desdobramentos na área educacional, denominados de Educação Performativa. Recorremos, igualmente, às ideias e às discussões, comumente presentes no campo da Educação e da Arte em prol de uma concepção de inerência das performances dos papéis sociais do(a) artista, docente, pesquisador(a) as quais, de início, evidenciamos. Por meio a presente escrita, ponderamos a necessidade de (re)conhecimento da natureza no que diz respeito à experiência educacional, ou seja, se torna cada vez mais urgente observar as nomenclaturas adotas em nossa área de conhecimento, indagando constantemente delas suas possíveis interferências e modos de atualização em práxis e contextos de emergência.

Palavras-chave: Artista; Professor(a); Docente; Educação Performativa; Inerência.

Abstract: Linked to the research group Laboratory for studies in Performative Education, Language and Theatricalities (ELiTe/UFPR/CNPq), we seek, through this 
article, to draw attention to the inherence of the performance of the social roles of artist, teacher and researcher in social dramas in the school. This requires a careful look at how these performances are conceived in the particularities of their practical and theoretical manifestations, in different studies, through the spellings by which they are distinguished. The recurrent use of two graphic signs, the backslash $(/)$ and hyphen $(-)$, to delimit what we are operating in the artistic do-thinking, as well as the contexts of art teaching and the research profession, provide support to enable the considerations developed here to be used to investigate the endorsement of these variables ( - ) in the written expression. The cornerstone of this research proposal consists of specific excerpts from Performance Studies and its developments in the area of education, where it is called Performative Education. We also invoke the ideas and discussions already common in the fields of Education and Art, in favor of a concept of inherence in the performance of the social roles of the artist, teacher and researcher that we demonstrate from the outset. Through this work, we reflect on the need to (re)acknowledge nature in relation to the educational experience, i.e., it is increasingly urgent to observe the nomenclatures adopted in our area of knowledge, constantly inquiring as to their possible interferences and updating the modes in praxis and emerging contexts.

Keywords: Artist; Teacher; Researcher; Performative Education; Inherence.

Resumen: Vinculados al grupo de investigación Laboratorio de estúdios en Educación Performativa, Lenguaje y Teatralidades (ELiTe/UFPR/CNPq), buscamos, mediante este articulo, promover consideraciones relativas a la inherencia de las performances de los papeles sociales del actuar artista, docente e investigador(a). Esto implica, por lo tanto, observar cuidadosamente las formas en que esas performances se conciben en las particularidades de sus manifestaciones prácticas y teóricas en diferentes estudios a través de las grafías de las que se distinguen. El uso recurrente de los signos gráficos de barra oblicua (/) y guion (-) para delimitar aquello que opera entre el hacer artístico, así como los contextos de la enseñanza del arte, y el oficio de la investigación proporcionan recursos para que, en las consideraciones aquí desarrolladas, podamos problematizar el respaldo de esas variables (/ -) en la expresión escrita. El marco de nuestra propuesta de investigación son extractos específicos de los Estudios de la Performance y sus ramificaciones en el área educativa, llamadas Educación Performativa. Acudimos, igualmente, a las ideas y discusiones ya comunes al campo de la Educación y del Arte a favor de una concepción de inherencia de las performances de los papeles sociales del(la) artista, docente, investigador(a) que destacamos en un principio. A través de este escrito, consideramos la necesidad del (re) conocimiento de la naturaleza con respecto a la experiencia educativa, es decir, se hace cada vez más urgente observar las nomenclaturas adoptadas en nuestra área de conocimiento, preguntándoles constantemente por sus posibles interferencias y modos de actualización en la praxis y contextos de emergencia.

Palabras clave: Artista; Docente; Investigador(a); Educación Performativa; Inherencia.

\section{Primeiras palavras}

Não é inaugural, ou até mesmo recente, a atualização dos discursos, nos diversos campos de atuação da Arte ${ }^{1}$, regida pela incumbência problematizadora e propulsora de novas maneiras de se fazer sentidos. Essa atualização significa, então, uma historicidade embasada no apelo às mudanças capazes de produzir consecutivas e infindáveis perspectivas, mediante os prismas, até então conhecidos, em favor de novos objetos a serem vislumbrados. 
Logo, concepções cristalizadas cedem espaço a discursos atualizantes, mais dinâmicos e abertos aos possíveis diálogos que emergem frente ao saber já conhecido. Reside sobre essa premissa o resgate, sempre que possível, das vozes, faladas e escritas, que fortaleceram e das que continuam a fortalecer as tramas da pesquisa.

Aproximamos, assim, os campos da Educação e da Arte e sobre o que deles, no tocante aos saberes, nos interessa especular, trinchar, aguçar. Em outras palavras, apresentamos a perspectiva que nos rege na arena das falas a respeito da temática em torno da Arte, do Corpo e da Educação, em uma proposta revisora das grafias pelas quais se tem difundido academicamente as performances dos papéis sociais do ser artista, docente e pesquisador(a).

Ora, se tratamos de performance, tratamos, igualmente, do corpo. Da corporeidade que se deslancha por entre aquilo que se produz no âmbito artístico em consonância ao lugar que por ela se opera no pedagógico e também na pesquisa. Ou seja, objetivamos, mais especificamente, olhar as maneiras como esses papéis sociais vêm sendo esquematizados no campo teórico e prático, a fim de que se notem lacunas relevantes às problematizações sem, contudo, deixarmos de considerar o fortalecimento das ideias entre a Educação e a Arte.

Isso significa, pois, orientar um olhar aos modos como tais performances - artista, docente e pesquisador(a) - são concebidas nos diferentes estudos por via das grafias nas quais são discriminadas, por exemplo: "arte-educador", "artista-docente", "artista/docente/pesquisador", ou outras grafias similares, pelas quais a inversão entre essas palavras, e/ou a mudança do vocábulo docente para professor(a) é possível, e mantendo-se o interesse por nós investigado.

O recorrente uso dos sinais gráficos de barra oblíqua ( / ) e hífen ( - ) para delimitar aquilo que se opera por entre o fazer artístico, assim como os diversos contextos do ensino da arte e o ofício da pesquisa, fornecem subsídios a fim da reflexão acerca do endosso dessas variáveis na expressão escrita e, principalmente, que possíveis concepções e/ou afetamentos às maneiras de escrever aludem nas performances sociais, as quais, por ora, evidenciamos.

Para isto, partimos de alguns pressupostos oriundos de teorias da performance - dramas sociais e estéticos, papéis sociais e comportamento restaurado - elaborados por teóricos do campo, a saber, Victor Turner, Richard Schechner e Erving Goffman. As ideias trazidas por meio a esse conjunto de autores adentram à esfera educacional pela qual nos referimos como Educação Performativa ${ }^{2}$. Recorremos, igualmente, às ideias e às discussões, comumente presentes nos campos da Educação e da Arte em prol de uma concepção/proposta de inerência das performances dos papéis sociais aqui desenvolvidas.

Buscamos refletir sobre como nosso aporte teórico tem contribuído à ampliação de novos olhares para o corpo e as Artes da Cena no âmbito educativo e, principalmente, como essa corporeidade artística e educacional tem se apresentado cada vez mais dinâmica e fluida por entre as cristalizadas fronteiras que insistem na não diluição entre a Arte e a vida.

Ainda nesse viés, concordamos com Freire (2011) acerca da necessidade de (re) conhecimento da natureza no que diz respeito à experiência educacional, ou seja, ao movermos com clareza em nossas práticas educativas se torna cada vez mais urgente questionar as 
nomenclaturas adotadas em nossa área de conhecimento, indagando constantemente delas suas possíveis interferências e modos de atualização em práxis e contextos de emergência.

\section{Algumas questões de performance(s)}

Amplo, interdisciplinar; se não, indisciplinado, os Estudos da Performance se constroem no diálogo teórico e prático entre diferentes escopos de estudos capazes de fecundar novas questões no âmbito das Ciências Humanas e nas inter-relações que suas temáticas possam oferecer à compreensão dos fenômenos sociais, sobretudo quando canalizadas na presença do corpo o principal objeto de investigação.

De pronto, significa perpassar por estudos que se interessam pelas marcas identitárias "que remodulam e ressignificam sujeitos, considerando seus corpos e suas narrativas com base em diferentes papéis sociais que exercem e/ou lugares sociais que ocupam" (GONÇALVES; GONÇALVES, 2018). Daí a capacidade de localizar e problematizar o corpo em contextos distintos, sobre as novas maneiras para interpretá-lo e na direção rumo à sua infindável produção de subjetividade e sentido.

Sentidos outros que pesquisas, desde as décadas de 60 e 70 do século XX, têm borrado e tornado cada vez mais indistintos, por exemplo, os limites entre a Arte e o campo da vida real. Tal indicação provém não apenas de pesquisadoras e pesquisadores na área da Arte, mas também da Antropologia, Sociologia e Filosofia (CARLSON, 2009). Neste artigo, destacamos algumas das contribuições de autores da pesquisa em performance como Richard Schechner (1985, 2000, 2012), Victor Turner (2015) e Erving Goffman (2014).

Ao tomar emprestado desses autores conceitos-chave para a problemática, que se circunscreve no interior da nossa escrita, consideramos, a partir das ideias de dramas, papéis sociais e comportamento restaurado, indicações e perspectivas a respeito de como as performances sociais de artista, docente e pesquisador(a) podem ser problematizadas na convergência entre o fazer artístico e o campo educacional, e como podemos desenvolver algumas reflexões acerca desse assunto.

Desse modo, ao que compele à Arte nos interessa olhar não à produção artística em sua especificidade, materialidade e/ou autoria das quais adentram procedimentos compositivos ou estéticos de quem a cria. Mas nosso enfoque está na maneira de conceber o/a artista que a elabora quando o/a mesmo/mesma se performa como docente e pesquisador(a). Do que se quer discorrer no âmbito educativo, a Educação Performativa se enviesa por meio aos Estudos da Performance em pesquisas que se voltam para o corpo em situações de ensino e de aprendizagem e, principalmente, como esse corpo interfere nas conjunturas educacionais ao operar sobre sua realidade outras possibilidades de ações reflexivas e comprometidas com a intervenção objetivada por emancipação (GONÇALVES; GABARDO JUNIOR, 2020). Voltamos, por enquanto, às delimitações mais abrangentes dos Estudos da Performance e, posteriormente, dedicar-nos-emos aos diálogos com a Educação Performativa. 
$\mathrm{Na}$ proposição de recortes que regem os Estudos da Performance, apresentamos, ainda, uma estratégica regida por uma contingência: cair na amplitude conceitual da própria performance. Em outras palavras, a interdisciplinaridade existente nesses estudos promove não somente a polissemia conceitual contida em seu nome, como, igualmente, a pluralidade de modos no trato conceitual quando tomada como aporte teórico, assim, ao entrecruzar múltiplos saberes e procedimentos metodológicos, antecipamos que o seu aprofundamento ou sua linearidade é algo demasiado pretensioso para a escrita que se segue. Os Estudos da Performance vêm expandindo nos últimos anos as noções de cotidiano, tomando-o como campo teatralizado (SCHECHNER, 2012), capaz de dar à vida ações mais ou menos ensaiadas e organizadas a partir de comportamentos predefinidos. Consideramos aquilo que é teatralizado na noção da própria teatralidade, em outras palavras, ao pensar o teatro como campo expandido, "é urgente o olhar para manifestações contemporâneas daquilo que é intrinsecamente teatral, mas não se encontra, necessariamente, atrelado à prática teatral in situ" (GONÇALVES; GONÇALVES, 2018).

Nessa mesma direção, as pesquisas antropológicas, propostas por Victor Turner, são confluídas por parte de uma teoria social dramatúrgica, em que um arranjo de conceitos é apropriado da área do teatro para serem refletidos metaforicamente ao campo social. A parceria de Turner, em meados da década de 1970, com o teatrólogo Richard Schechner, fomentou o alicerce teórico do que se propôs como performance, cuja teatralização dos aspectos da vida cotidiana embasou o que se pode entender, em primeira instância, por dramas.

Os dramas sociais e os dramas estéticos são tratados como processos convergentes entre diálogos que se operam nas relações do campo social e do campo dramático. O teatro como drama estético ritualiza as suas formas de operação e passa a criar espaços e tempos simbólicos e/ou ficcionais (SCHECHNER, 2000). Os dramas sociais, embora tenham uma carga de ações socialmente teatralizadas, têm, na vida ordinária, estruturas de performances, ações humanas capazes de gerar fases de ruptura, crise, ação reparadora e reintegração das normas ${ }^{3}$. Os dramas sociais comportam o público, envolvendo-o em seus rituais - religiosos, políticos, de jogos, de esportes, cerimoniais -, enquanto que os dramas estéticos são orientados para a consciência do público, integrando, pois, os atores na performance. Schechner passou a encontrar, nos dramas sociais de Turner, similaridades com o teatro e ampliou as suas maneiras propositivas de operar nas Artes Cênicas. Nota-se, nesse percurso, a forte corrente de vanguarda norte-americana e europeia com experimentações capazes de provocar crises na lógica dicotômica entre Arte e vida. Em outras palavras, ao trazer o cotidiano para a cena e/ou romper com o distanciamento entre obra-público/público-obra, confere à Arte espaços para ritualizar com o comum e o comum como modo de ser estudado por meio da Arte.

A palavra drama abarcaria, assim, o seu significado para qualquer tipo de representação cultural específica (SCHECHNER, 2012) e, ao mesmo tempo, o drama expressaria o nosso jeito nato de nos manifestarmos para nós mesmos e de declararmos onde o poder e o significado estão e como eles são distribuídos (TURNER, 2015). 


\begin{abstract}
Para mim, a antropologia da performance é parte essencial da antropologia da experiência. De certa forma, como Dilthey defendeu diversas vezes, todo tipo de performance cultural, incluindo rituais, as cerimônias, o carnaval, o teatro, a poesia, é em si mesmo uma análise e uma explicação da vida. (...) Aqui a etimologia de "performance" pode nos dar uma pista útil, pois o termo nada tem a ver com "forma", mas é derivado do francês arcaico parfournir, "completar" ou "fazer completamente". Uma performance, portanto, é o apropriado finale de uma experiência. (TURNER, 2015, p. 16).
\end{abstract}

Para Turner, a performance traz completude à experiência. Dentre as múltiplas fronteiras, o não limite da performance canaliza-se em sua capacidade de produzir experiências, quer seja no campo ficcional ou na vida real. Os rituais, mencionados breve e anteriormente, configuramse para Schechner (2012) como aqueles que ocorrem no âmbito sagrado e secular, cujas performances dos indivíduos demarcam presenças que invocam memórias e comportamentos duplamente exercidos.

Goffman (2014) traz o conceito da atuação dos papéis sociais por meio de uma análise da representação social como dramaturgia, uma metáfora para a vida real. São apontados por ele os papéis sociais, os quais performamos, semelhantes a atores no palco. A ação englobaria, assim, uma noção comunicacional e performática tomada diante dos outros atores sociais.

Ao agenciar as condutas comportamentais e performáticas, aperfeiçoam-se as ações corriqueiras do cotidiano ou, até mesmo, condutas elaboradas, ocorridas em eventos de maior importância social. Significa compreender que "o relacionamento social comum é montado tal como uma cena teatral, resultado da troca de ações, oposições e respostas conclusivas dramaticamente distendidas" (GOFFMAN, 2014, p.85), ou seja, o "mundo todo não constitui evidentemente um palco, mas não é fácil especificar os aspectos essenciais em que não é". (GOFFMAN, 2014, p.85).

É notável na perspectiva de Goffman que a performance dos papéis sociais consiste nas ações que os sujeitos realizam em dado período marcado por sua presença frente a outros observadores, e na influência que esse possa ter sobre eles. Goffman não enfatiza um caráter de consciência da performance, o que, para alguns estudiosos do campo, levantaria a possibilidade de um engajamento na ação sem necessariamente ter a consciência desta (CARLSON, 2010).

Nos Estudos da Performance de Richard Schechner, a performance está mais atrelada ao corpo do performer do que à comunidade em que ele se mostra socialmente. Assim, Schechner adentra proeminente em sua teoria, cuja proposta de comportamento restaurado - restored behaviour - não apenas traz outros horizontes à perspectiva de Goffman, como também se faz interessante ao percurso das reflexões desenvolvidas em nosso estudo. Para o autor, o comportamento restaurado é

(...) simbólico e reflexivo: comportamento não vazio, mas carregado multivocalmente de transmissão de significados. Esses termos difíceis expressam um único princípio: O eu pode atuar ou/como outro; o eu social ou transindividual é um papel ou um conjunto de papéis. Comportamento simbólico e reflexivo é o enraizamento no teatro do processo social, religioso, estético, médico e educacional. Performance significa: nunca pela primeira vez. Isso significa: pela segunda à enésima vez. A performance é "comportamento duas vezes vivenciado". (SCHECHNER, 1985, p.36). 
O contato com o escrito supracitado de Schechner permite entender o comportamento restaurado como ação duas vezes experienciada, e isso requer dizer que as ações cotidianas são remontadas a partir dos rearranjados comportamentais em circunstâncias anteriormente vividas pelo sujeito na condição sociopolítica e cultural da qual faz parte. Para que se possa entender o que se quer por comportamento restaurado, o teatrólogo expõe a necessidade de analisar os atos que estão para além do corpo que performa, ou seja, trata-se das condutas ou sequências bem-sucedidas, as quais são separadas e conscientes dos sujeitos que as realizam.

Dito de outro modo, "o comportamento pode ser armazenado, transmitido, manipulado, transformado. Os performers entram em contato com recuperação, lembrança" (SCHECHNER, 1985, p.36), aduzidas em suas ações diárias; assim, os indivíduos performam hábitos e adquirem condutas. Performar o papel social nas lentes do comportamento restaurado incumbe-nos uma atitude, pois "podemos fazer ações sem pensar, mas, quando pensamos sobre elas, isso introduz uma consciência que Ihes dá a qualidade de performance". (CARLSON, 2010, p. 15).

Significa, então, considerar a ação corporal do sujeito como um ato atualizante e consciente frente à sua realidade e às circunstâncias que o envolvem, as quais, por intermédio e intervenção do seu corpo, (re)organiza as lógicas de uma dada experiência social. Schechner dá ao comportamento restaurado uma ação simbólica e reflexiva, jamais vazia. $O$ autor atribui a este comportamento um significado de multivocalidade: um eu pode se performar como um outro, um papel ou vários papéis sociais.

Os diálogos teóricos entre Goffman e Schechner apresentam distinções, todavia não se comprometem. $\mathrm{O}$ que queremos com essas abordagens é estabelecer que os papéis que performamos socialmente estão carregados de sentidos e interferências ritualizadas no campo das relações humanas. Esse amplo jogo de discursos comunga por um olhar mais atento ao corpo e para suas ações de interatividade e capacidade inventiva no campo da cultura.

Podemos considerar, pois, dramas, papéis sociais e comportamento restaurado como condições ímpares àquilo que se possa saber acerca de performance. Ao reconhecermos a teatralidade como sentido expandido capaz de levar a arte à vida e a vida à arte, novas percepções para se pensar os fenômenos humanos emergem e se tornam caminhos em prol dos nossos procedimentos metodológicos e das maneiras pelas quais analisamos o corpo na contemporaneidade. Esse último cada vez mais investigado na égide do cruzamento entre campos e epistemologias, portanto uma condição nata para pesquisas que se constroem nas/ das/sobre fronteiras.

\section{Algumas questões de Educação}

Compele-nos percorrer outro lugar da interface dos Estudos da Performance nas pesquisas em Ciências Humanas: a Educação. Sendo este mais um recorte capaz de nos dirigir para outra amplitude de conceitos, porém indispensável se faz notar os escritos que vêm sendo guiados em direção aos dramas e aos papéis sociais que são cotidianamente experienciados 
em situações de ensino e aprendizagem. Tomamos, a esse modo, uma possibilidade de viés teórico/prático e metodológico/analítico por vias dos modos como a performance tem estimulado nossas inquietações acerca do corpo no campo da Educação. Um minucioso acompanhamento por entre os escritos que objetivam aproximar os Estudos da Performance e a Educação demostra a recente fomentação em torno dessa ideia. Entretanto, o aumento desses estudos no cenário acadêmico revela uma certa tendência e/ou vertente exploratória de acordo com os interesses específicos dos seus/suas pesquisadores/pesquisadoras, adotados, a partir deles/delas, nomenclaturas outras, como notado em autores/autoras como Pineau (2010), Pereira (2012) e Gonçalves (2020). A esta forma de propor perguntas ou hipóteses para o cerne da pesquisa educacional, a denominação Educação Performativa será considerada, neste trabalho, com base nos pressupostos de Gonçalves e Gabardo Junior (2020).

Podemos notar por meio desse conjunto bibliográfico que os dramas sociais educacionais, assim como nas prerrogativas de Turner, comungam, igualmente, trajetos constantemente engajados por ruptura, crise, reparo e reintegração das normas. Isso requer sinalizar a sinuosa cultura dos meios formativos, para o qual o corpo se apresenta como espaço interlocutório. Nisso reside um importante apontamento a ser interiorizado no presente texto para qual aquilo que é corporal se faz fundamental para propor qualquer método e metodologia no campo educativo.

Portanto, apresentamos e justificamos a necessidade de pensar um educar performativo por compreender o ensino e a aprendizagem do/no/sobre o corpo uma espécie de textotecer, como já dito anteriormente por Schechner (2010). Uma Educação impulsionada por tecituras ganha atributo metafórico a fim de "colocar sob fios performáticos um tecer do corpo diante da singularidade complexa que é encontrada em cada trama educativa" (GABARDO JUNIOR, 2020, p. 56). Significa, então, vislumbrar costuras de fios corporais e educativos que oportunizam a escuta da voz em local e situação que ainda impera o silenciamento do corpo em urdidura de aprendizagem.

Ainda envoltos na metáfora de texto-tecituras, Schechner nos permite pensar o corpo na Educação como texto em seu sentido mais expandido: é escrita, dança, gesto, lugares, processos de crescimento, florescimento e decadência. Corporeidade é múltiplos fios "tramados e destramados em diferentes tecidos de ação e significado" (2010, p. 30). Tal pensamento nos incube às noções da Educação - como - Performativa. Requer dar ao corpo uma qualidade de fio capaz de conduzir e desenlaçar os nós dados por condições de uma formação administrada. "O que se quer dizer está na decisão - não imparcial e nada desinteressada - de instigar corporeidades na continuidade de prolongação das suas vozes" (GABARDO JUNIOR, 2020, p. 56), o que nos leva à clareza de que os corpos continuamente falam, ao tomar nesse ato de escuta resultados de comportamentos cada vez mais restaurados.

Isso torna os Estudos da Performance, sobretudo no campo da Educação, uma forma de comunicação multicêntrica e periférica (PEREIRA, 2012). Multicêntrica porque se encontra na sua base o entre-lugar, a fronteira que resiste em dar ao corpo uma única conotação 
expressiva e, desse modo, se faz indisciplinada, porquanto como conhecimento, se justifica na capacidade renovadora de atribuir aos sujeitos novos papéis sociais, comportamentalmente restaurados. Periférica justamente por recrutar às suas discussões aquilo que vasa pelas bordas, o que escapa dos limites ainda impostos em nosso sistema de ensino. Um confronto em prol de colocar em cena os dramas sociais que, marginalmente, invadem a escola, as universidades, os espaços de pesquisa e a produção do saber.

Por essa razão, a Educação Performativa impulsiona o acolhimento dos trânsitos invisibilizados e apequenados entre o dentro e o fora das instituições de ensino, ao buscar desse mover o discurso contido no próprio corpo. Um extrapolar para além das questões pedagógicas, trata-se de questões mais amplas, da produção infinita de linguagens, de discursos, logo, performativas. A discussão, pois, estaria mais ligada aos processos que são pelo corpo produzidos e as variadas leituras, contextualizações e interpretações que os sujeitos possam realizar do mundo e de si próprios.

Dito de outro modo, pela Educação Performativa se dariam a ver os desafios de se lidar com aquilo que está para além do ser/atuar como sujeitos da educação. Postularia problematizar o recebimento do que é marginalizado pela cultura institucionalizante, destacando, também, as suas influências reais nos processos de ensino e de aprendizagem. Estaria dado o lugar à resistência capaz de suspender da escolarização, condutas esperadas e sentido sucateado pela tradição. Haveria espaço para o devir do inusitado, e para os saberes das invisibilidades (re)significadas. (GONÇALVES; GABARDO JUNIOR, 2020, p. 105).

A chamada de atenção - se não igualmente um convite - está para um "atrevimento no que se refere a possíveis desorganizações do discurso administrativo e de uma resistência quanto à própria ideia de teorizar o corpo escolar de forma que ele se enquadre em um ou outro arcabouço epistemológico-científico" (GONÇALVES, GONÇALVES, 2018, p. 146) ou, como bem lembra Richard Schechner (2000), a possibilidade de um eu se performar como vários outros. Nunca uno, mas uma multiplicidade de atuações sobre a vida. À vista disso, as performances "funcionam como atos de transferência vitais, transmitindo o conhecimento, a memória e um sentido de identidade social" (TAYLOR, 2013, p. 27), legitimando-as em seu sentido epistemológico como teoria de base em estudos social, artístico e educacional.

Interessa-nos aqui o caráter fronteiriço da performance, porque encontramos nele lugar de discurso e provocação. Pensar os pressupostos de dramas, papéis sociais e comportamento restaurado para com os interesses de uma Educação requer novas balizas, na mesma medida em que não há aqui um interesse delimitador, por isso sempre capaz de se atualizar. Requer igualmente tomar a performance como acontecimento discursivo, afinal, ao se adotar o lugar de fronteira, aderimos simultaneamente indistinção entre corpo e contexto(s) (GONÇALVES, 2020).

Portanto, colocar em discussão o performar do papel social de ser/atuar/estar artista que penetra as urdiduras da Educação nos convoca a problematizar alguns aspectos em torno dessa temática. A seguir, destacamos e também propomos alguns pontos de ponderação no uso de termos frequentemente utilizados e disseminados no campo teórico e prático dos estudos em Educação e Arte que buscam situar essas performances sociais - artista, docente e pesquisador(a) - em variados contextos, apresentando, pois, atenção às formas como eles se in(e)screvem. 


\section{Algumas questões de escrita(s)}

O foco, todavia, despenderia ponderar como os papéis socialmente performados de artista, docente e pesquisador(a) possam ser refletidos à luz dos Estudos da Performance como lente de fenômenos sociais e da Educação Performativa, por sua capacidade de aproximar a performance às discussões do corpo no campo educacional.

O que alçamos saber se limita, num primeiro momento, pelas formas como esses papéis sociais são teorizados como esfera das questões artísticas que se entrecruzam nos espaços didático-pedagógicos e, também, na pesquisa. Essa última compreendida como processos esquematizados de cunho teórico, prático e artístico vinculados à produção acadêmica.

A pontualidade do nosso discurso se restringe, sobretudo, no como essas questões são teorizadas, considerando-se suas grafias em estudos científicos. Distanciamos nosso texto de um levantamento minucioso do número de escritos e/ou os escopos em que esses estudos se contextualizam, e nos posicionamos, todavia, como performes leitores, interessados por essas questões, implicadas também às nossas leituras desenvolvidas nos últimos anos por meio da busca no Catálogo de Teses e Dissertações da CAPES, periódicos e anais de eventos. Parte dessas buscas são realizadas através de indicadores como artista/docente/pesquisador; artista-docente-pesquisador; artista-docente; professor-artista; ou outras grafias similares, pelas quais a inversão entre essas palavras, e/ou a mudança do vocábulo docente para professor(a) é possível, e mantendo-se o interesse por nós investigado.

O foco, contudo, reside principalmente nas possíveis concepções ou afetamentos que essas maneiras de escrever aludem nas performances sociais, as quais evidenciamos: o performar social de artista, docente e pesquisador(a). Para tanto, retomamos de longa data o livro A formação de professores de Arte: diversidade e complexidade pedagógica, da autora Maria Cristina da Rosa (2005). Sua escrita desperta curioso interesse ao ponderar que "o professor deverá ser também um pesquisador, o que poderia se traduzir para a nossa questão específica, que o professor deverá também ser um artista" (ROSA, 2005, p. 21). O lugar de interlocução no qual Rosa dialoga é a formação de professores, especificamente dos licenciados em Artes Visuais, porém sua fala muito pode ser (re)visitada e ampliada às questões acerca do corpo e as Artes da Cena, sendo a Educação a principal condutora nessa pensante travessia.

O que nos anima a nos movermos por entre essas linhas reside no pressuposto de que o/a professor(a) como atuação - social, cultural e política - se performa, ou, ao menos, se espera que sim, nas vias da pesquisa. Ou seja, como pesquisador(a) acerca do que estuda, como especulador(a) sobre o seu próprio ofício, ou, tal qual tomamos contemporaneamente em nossos estudos, como performer da sua formação continuada.

Posteriormente, ao trazer esse pressuposto às discussões artísticas e educacionais, a autora novamente toma como certo que o professor de arte deverá também ser um artista. Talvez nos compete lembrar que ainda vivenciamos um vir a ser das questões mais amplas 
do ensino da arte em nosso país, isto é, as especificidades das linguagens artísticas das Artes Visuais, da Dança, da Música e do Teatro em cursos superiores de licenciatura ainda não abrangem a totalidade de oferta que esse campo profissional capacita vivenciar, e muito se sabe que os prescritivos nacionais para a educação básica continuam a fazer ambíguas as normas da lei. Essa problemática permite aos profissionais ensinarem arte sem possuírem, minimamente, graduação na área (VASCONCELLOS; STORCK; MOMOLI; 2018).

Sem dúvida, este é assunto para outro momento. Porém, ao tomar como certa a performance artística consonante à performance do/da educador/educadora e, ao mesmo tempo, ter como pronta a figura do/da pesquisador(a) na performance docente, quais sentidos ainda operam quando esses papéis sociais são evidenciados nos discursos textuais que abordam suas experiências nos mais diferentes âmbitos educacionais? Mais especificamente, nossa análise aponta para os sinais gráficos de barra oblíqua (/) e hífen (-) nas expressões orientadas nas inter-relações entre as performances sociais de artista, docente e pesquisador(a).

Na linguística, o uso de barra oblíqua cria a ideia de disjunção para a qual um termo, ao ser colocado ao lado de outro e separado por esse sinal gráfico, transmite na leitura o significado ou. Seu uso também englobaria palavras aparentadas ou em oposição. Portanto, artista/docente/pesquisador expressaria um papel social ou outro. O sentido aparentado não apresenta encaixes lógicos na língua. Embora as três palavras possuam sua etimologia do latim - ars para artista; professus para professor; docens para docente e perquisitor para pesquisador -, são termos com ênfases diferentes. Já o sentido de oposição contido no sinal gráfico da barra oblíqua tornaria incoerente a concepção de papéis sociais que se complementam em performances cotidianas. Talvez esse seja o sentido que mais comprometa a lógica integralista desses papéis sociais contida no interior de textos que buscam expressar performances mais subsequentes e integradas.

Outra análise possível de ser percebida é o recorrente uso do hífen. A união semântica desse sinal gráfico é notada por entre os textos como uma tentativa de tornar unificados os papéis sociais aqui discutidos, assim descritos como artista-docente-pesquisador; arteeducador; professor-artista. Porém, uma análise mais atenta nos orienta, minimamente, indagar sobre a real necessidade e os sentidos interiorizados nessas formas de expressão escrita ou, até mesmo, compará-las com outras áreas do conhecimento que, igualmente, entrecruzam uma determinada atuação profissional com o licenciar e/o pesquisar.

Voltemos à autoria, à Rosa, cujas reflexões apresentam a pressuposta ação das performances de artista, professor(a) e pesquisador(a) que nos conduzem à percepção dos excessos dessas grafias. Dito de outro modo, ao tomar como pressupostos os papéis sociais entre o fazer artístico, docente e pesquisador(a), o uso do hífen poderá ser repensado. O avanço que propomos à fala de Rosa se localiza na constatação da autora que, ao conceber esses papéis sociais em ação pressuposta, os atualiza como um ideário de base ao que buscamos reivindicar e nos apropriarmos nas garantias em torno das nossas linguagens específicas. 
O termo arte-educador, por exemplo, se assenta em movimentos de lutas das classes artísticas que buscavam, durante a segunda metade do século XX, por legitimação da formação e da ocupação dos/das artistas como educadores/educadoras em espaços como escolas e cursos-livres. Bredariolli indaga se as nomenclaturas adotadas em uma área de conhecimento interfere em sua atualização ou em sua práxis. A mesma autora conclui que cada expressão cunhada "guarda uma sobreposição de histórias peculiares, porém, não deixam de se correlacionar, entramadas em uma história comum, a do ensino da arte no Brasil" (2019, p. 100), e ressalta que cada uma delas "identifica práticas e concepções específicas, vinculados a certos tempos e lugares, a certos contextos de emergência" (2019, p. 100).

Portanto, tanto as ideias de Rosa como de Bredariolli corroboram para as inquietações contidas no interior do presente texto. Afinal, quais os sentidos e/ou repercussões dessas grafias quando vistas na perspectiva dos Estudos da Performance na Educação? Ou, como uma teoria da performance no campo educacional - Educação Performativa -, aduz para novas balizas e para o borrar das fronteiras em torno desses termos e, principalmente, nos diálogos que emergem do cenário contemporâneo da Arte no território educativo?

Para responder esses questionamentos, o olhar crítico, contudo, versa para além de hifens e barras oblíquas, porque se justifica na urgente postulação de uma concepção de inerência dessas performances, sobretudo quando colocadas na arena das discussões que envolvam questões mais amplas ou, até mesmo, mais pontuais entre a Arte e a Educação.

\section{Uma proposta de inerência performativa}

Após todos os apontamentos, um dado se coloca como certo: o compromisso das diversas leituras na aproximação crítica entre a Educação e Arte, e o enfrentamento do distanciamento que o performar cotidiano artístico, pedagógico e investigativo possa enfrentar em realidades educativas lineares e dicotômicas. O apagamento entre uma performance e outra certamente é um dos aspectos a serem seriamente pensados a partir da pressuposição desdobrada na fala de Rosa. Ou, como tomado anteriormente de Schechner: tramas e destramas educativas sobre distintos tecidos de ações e significados, por isso, urgente de ponderação e de novas perspectivas.

É válido relembrar Freire quando ele diz:

Outro saber fundamental à experiência educativa é o que diz respeito à sua natureza. Como professor preciso me mover com clareza na minha prática. Preciso conhecer as diferentes dimensões que caracterizam a essência da prática, o que me pode tornar mais seguro no meu próprio desempenho. (FREIRE, 2011, p. 67).

Poderíamos compreender muito bem a natureza em práticas performativas na íntima relação que estas tecem e cruzam nos contextos de artistas que se performam profissionalmente pela Educação e a pesquisa. Referimo-nos à Educação com o entendimento de que nem todos/ todas os/as artistas vislumbram se envolver com práticas pedagógicas. Contudo, mencionamos a contextos outros que englobam artistas que se enviesam e tecem no pedagógico, seja via 
pesquisa científica, seja nas aproximações atentas que possam levá-los/levá-las a desenvolver desde a educação básica até o ensino superior, dos ateliês aos cursos livres, em que o aprendizado se constitui como atividade pragmática.

Ricardo Basbaum (2008) traz no seu escrito Amo os artistas-etc corroborações interessantes ao dar o adjetivo et cetera para aquelas qualidades outras que perpassam o ofício do ser artista.

'Artista' é um termo cujo sentido se sobre-compõe em múltiplas camadas (o mesmo se passa com a 'arte' e demais palavras relacionadas, tais como 'pintura', 'desenho', 'objeto'), isto é, ainda que seja escrito sempre da mesma maneira, possui diversos significados ao mesmo tempo. Sua multiplicidade, entretanto, é inevitavelmente reduzida apenas a um sentido dominante e único (com a óbvia colaboração de uma maioria de leitores conformados e conformistas). Logo, é sempre necessário operar distinções de vocabulário. $O$ 'artista-etc' traz ainda para o primeiro plano conexões entre arte\&vida (o 'na-artista' de Kaprow) e arte\&comunidades, abrindo caminho para a rica e curiosa mistura entre singularidade e acaso, diferenças culturais e sociais, e o pensamento. (BASBAUM, 2008, p. 63).

Ao migrarmos as ideias de Basbaum para o cenário de dramas sociais educativos, o performar artista, docente e pesquisador(a) vislumbra sentidos de comportamentos restaurados. Performances de vida, repertórios lembrados e esquecidos ou, como um arsenal de bagagens das vivências pessoais e coletivas que, assim como sequências bem-sucedidas, são, ao mesmo tempo, manifestações da cultura que trans(formam) o corpo, mas que, igualmente, o transpassa, o afeta e são por ele modificadas.

Em outras palavras, os dramas cotidianos do vivenciar a escola ou a universidade, por exemplo, dão ao artista, docente e pesquisador(a) a possibilidade de atualização desses papéis sociais. Isso posto, caberia envolver sobre essas performances uma visão mais dinâmica e não hierárquica, pois, no borrar das fronteiras entre o performar artista, docente e pesquisador(a), estão os repertórios pessoais elaborados em descobertas de lógicas e estratégias acerca do que o corpo é capaz de organizar no percurso da sua própria formação, sempre continuada, não estática e não dicotômica. Assim, as escolhas didáticas do/da professor(a) não se apartam do corpo que performa esse outro eu artista. A bagagem do seu experienciar Arte, os seus estudos, as inúmeras esferas da vida ordinária atravessam, até mesmo, as suas escolhas de conteúdo. Como dito anteriormente: nunca uno.

Nisso prescinde nossa premissa: ao tomarmos de Rosa a ideia de pressuposta concepção de que todo(a) professor(a) é um(a) pesquisador(a), e que todo(a) professor(a) de arte é um(a) artista, findaríamos as grafias que, de alguma maneira, não se atrelam com o sentido conjunto que esses papéis sociais operam no cotidiano educacional. Não se trata de ignorar as singularidades das atuações das performances sociais que aqui evidenciamos, sobretudo consideramos que até mesmo essas performances são contaminadas por outras áreas do indivíduo social, cultural e político que somos. Mas o interesse se localiza no borrar das fronteiras capaz de contrapor lógicas que ainda sustam o senso comum de quem não sabe fazer, ensina. Pelo contrário, o esforço intelectual está na inerência de uma tríade que sustenta a experiência artística, tanto de quem ensina e pesquisa. Morandi contribui na reflexão ao apontar: 


\begin{abstract}
A desvinculação das funções de artista e professor é uma questão polêmica. Todos nós sabemos que não basta ser um bom artista para ser um bom professor [e pesquisador]. No âmbito escolar, as diferentes implicações pedagógicas que envolvem o ensino devem ser conhecidas e trabalhadas coerentemente com a proposta da escola [da universidade, do ateliê, academias de artes cênicas, estúdios de dança, etc.]. Dessa forma, o conhecimento pedagógico faz-se importante para aqueles que optam pela carreira docente. Mas a especificidade e o aprofundamento das linguagens também geram a necessidade de um conhecimento artístico mais amplo e consistente, e que passa pela essencial experiência (prática) artística. (MORANDI, 2006, p. 85, ênfase nossa).
\end{abstract}

É importante acrescentar à fala de Morandi, que até mesmo o ofício de educar promove nos espaços educacionais a oportunidade de experimentação e produção artística do(a) docente de arte. Nota-se que o próprio processo pedagógico pode se tornar produção poética daquele/daquela que ensina arte, capaz de compartilhar sua criação com os/as estudantes e com a comunidade escolar, a fim de tecer novos diálogos e possibilidades entre sua pesquisa em Arte e os espaços por onde atua. Nisso reside uma aposta na qualidade comunicacional multicêntrica da performance, condição essa capaz de desestabilizar visões que não integram e que não tomam a inerência performativa, se não igualmente performática, de se performar artista, docente e pesquisador(a) em espaços de ensino. Portanto, ao tratarmos de um eu pesquisador(a), consideramos intrínseca a articulação teórica e prática de um eu artista e de um eu professor(a), seja qual for a predominância das performances em exemplificações e contextos. Significa, então, que ao lermos no texto sobre o/a professor(a) que atua na sala de aula, entendase, nesta mesma escrita, a inclusão imediata do/da artista e do/da pesquisador(a) que fazem o ato performativo de docente uma ação possível.

Isto significa tornar quem lê consciente de que a forma pela qual se escreve a performance social artística, pedagógica e pesquisadora nem sempre abarcará o dinamismo daquilo que se dá em dramas escolares cotidianos, mas que, ao considerá-los como uno, e ações de comportamentos restaurados, mesmo que nos textos apenas uma das performances seja evidenciada por escrito, os demais papéis sociais estarão, igualmente, ali incluídos/tramados/ enviesados. Ao se tornarem conscientes das suas performances - artísticas, pedagógicas e como pesquisadores/pesquisadoras -, os sujeitos propiciam espaços para "exploração de estruturas e modelos de comportamento alternativos e novos" (CARLSON, 2010, p. 24). Logo, o performar do/da artista no ofício de educador(a) abre novas lacunas para rupturas, crises, reparações e integrações dos modos de atuar dentro da escola, da universidade, dos ateliês, em estúdios, etc. Uma performance de inerência atrela-se a uma Educação que se pensa performativa e performaticamente, à medida que, por meio do corpo do sujeito que faz Arte, que ensina e pesquisa, ampliam-se os discursos, inovam-se as ferramentas e se atualizam os contextos por onde o fazer educacional e o artístico são refletidos nas formas peculiares de ensinar e nas maneiras inventivas para a sua aprendizagem.

\title{
Algumas considerações
}

Os Estudos da Performance na interfase com o campo educacional - Educação Performativa -, então, abarcaria modos operantes para pensarmos o corporal de professores 
e professoras, cuja Arte e o próprio corpo coabitam o universo educacional, dando aos educadores/educadoras condições de refletirem as suas performances em espaços de ensino, e oferecerem a esses locais características novas, atualizantes, afinal, "a performance não é um espelho passivo das mudanças sociais se não uma parte do complicado processo de regeneração que produz mudanças" (SCHECHNER, 2000, p. 38), por essa razão as grafias necessitam ser repensadas quando nos voltamos atentamente para tais contextos peculiares de ensino e consideramos a sua forma escrita e compartilhada.

Conecta-se nesse pensar e propor uma performance de inerência a capacidade de tê-la como pressuposto nos lugares dos quais devemos e desejamos ocupar como artistas licenciados/licenciadas diante da oferta profissional a nós disponível em espaços educacionais no país. Mesmo cientes das problemáticas que cercam essa questão, além da falta de professores/professoras licenciados/licenciadas, em diversas escolas do território nacional, e até mesmo a escassa oferta das atividades artísticas nos currículos escolares, é da constatação e defesa dessa inerência do/da artista, docente e pesquisador(a) - a partir da especificidade da linguagem da sua formação -, que passamos a fortalecer os discursos na elaboração de editais para concursos públicos, no enfrentamento crítico diante da insistente e questionável polivalência, e darmos manutenção às pautas em favor de profissionais da área em qualquer nível e oferta de ensino no Brasil. Entendemos, portanto, a presença da barra oblíqua e do hífen como reafirmação de algo que aqui tomamos como performances pressupostas e, ao nos questionarmos como essas grafias se apresentam contemporaneamente, tornamos a colocálas a uma revisão necessária. A perda do espaço da arte nas prescrições da Base Nacional Comum Curricular e a diminuição da oferta de atuação profissional que esse cenário traz requerem dessa inerente tríade estratégias e comportamentos restaurados em consequência de dramas sociais educacionais mais estáveis. Performances de papéis sociais mais críticos e atentos ao nosso tempo, capazes de conectar-se à inerência de uma Educação que se pensa performaticamente, à medida que, por meio do corpo do sujeito que faz Arte, que ensina e pesquisa, ampliam-se os discursos, inovam-se as ferramentas e se atualizam os contextos por onde o fazer artístico e o educacional são refletidos nas formas peculiares de ensinar e nas maneiras inventivas para a sua aprendizagem.

\section{Referências}

BASBAUM, Ricardo. Você gostaria de participar de uma experiência estética? (+NPB). 158 f. Tese (Doutorado em Artes Visuais) - Escola de Comunicação e Artes da Universidade de São Paulo. São Paulo, 2008. Disponível em: https://teses.usp.br/teses/disponiveis/27/27159/tde11052009-150004/publico/5064856.pdf. Acesso em: 08 mar. 2020.

BREDARIOLLI, Rita Luciana Berti. Histórias sobre arte, educação e política: articulações para construção de identidades docentes em um contexto Latino Americano. In: LIMA, Sidney Peterson Ferreira de; AUGUSTOWSKY, Gabriela, Instantes-já da formação docente em Artes. São Paulo: Terracota, 2019. p. 96-101. 
CARLSON, Marvin. Performance: uma introdução crítica. Tradução de: DINIZ, Thais. F. N; PEREIRA, M. A. Belo Horizonte: Editora UFMG, 2009.

FREIRE, Paulo. Pedagogia da autonomia: saberes necessários à prática educativa. Rio de Janeiro: Paz e Terra, 2011.

GABARDO JUNIOR, Jair Mario. Ensino da dança e a Educação Performativa: possibilidades de corpo na (re)criação do espaço escolar. 165 f. Dissertação (Mestrado em Educação) - Setor de Educação, Universidade Federal do Paraná. Curitiba, 2020. Disponível em: https://acervodigital. ufpr.br/handle/1884/67882. Acesso em: 17 nov. 2020.

GOFFMAN, Erving. A representação do eu na vida cotidiana. Tradução de: RAPOSO, Maria C. 20. ed. Petrópolis: Vozes, 2014.

GONÇALVES, Michelle B.; OLIVEIRA, Odissea B. Sentidos de escola em performance: um estudo na licenciatura em educação do campo. Revista Educação e Cultura Contemporânea, Rio de Janeiro, v. 17, n. 49, p. 392-441, jul./set. 2020. Disponível em: http://periodicos.estacio.br/index. php/reeduc/ article/view/7825. Acesso em: 20 jul. 2020.

GONÇALVES, Michelle Bocchi.; GABARDO JUNIOR, Jair Mario. Educação performativa: travessias. In: GONÇALVES, Jean Carlos; GARANHANI, Marynelma Camargo; GONÇALVES, Michelle Bocchi. Linguagem, corpo e estética na educação. São Paulo: Hucitec, 2020. p. 97-108.

GONÇALVES, Jean Carlos; GONÇALVES, Michelle Bocchi. Teatralidade e Performance na pesquisa em Educação: do corpo e da escrita em perspectiva discursiva. Educar em Revista, Curitiba, v. 34, n. 67, p. 139-155, 2018. Disponível em https://revistas.ufpr.br/educar/article/ view/56081/34711. Acesso em: 05 fev. 2020. DOI: 10.1590/0104-4060.56081

MORANDI, Carla. A dança no ensino de arte. In: STRAZZACAPPA, Márcia; MORANDI, Carla. Entre a arte e a docência: A formação do artista da dança. Campinas: Papirus, 2006. p. 77-94.

PEREIRA, Marcelo de Andrade. Performance e Educação: Relações, significados e contextos de investigação. Educação em Revista, Belo Horizonte, v. 28, n. 1, p. 289-312, 2012. Disponível em: http://www.scielo.br/pdf/edur/v28n1/a13v28n1.pdf. Acesso em: 8 fev. 2020. DOI: https:// doi.org/10.1590/S0102-46982012000100013

ROSA, Maria Cristina. A formação de professores de Arte: Diversidade e complexidade pedagógica. Florianópolis: Insular, 2005.

SCHECHNER, Richard. Performance e Antropologia de Richard Schechner. (Org.). LIGIÉRIO, Zeca. Rio de Janeiro: Mauad X, 2012.

SCHECHNER, Richard; ICLE, Gilberto; PEREIRA, Marcelo de Andrade. O que pode a performance na educação? Uma entrevista com Richard Schechner. Educação e Realidade, Santa Maria, v. 35, n. 2, p. 23-35, 2010. Disponível em: http://seer.ufrgs.br/index.php/educacaoerealidade/ article/view/13502/7644. Acesso em: 05 fev. 2020.

SCHECHNER, Richard. Performance: teoría y prácticas interculturales. Buenos Aires: Libros del Rojas, 2000.

SCHECHNER, Richard. Between theatre \& anthropology. Philadelphia: University of Pennsylvania Press, 1985. 
TAYLOR, Diana. O arquivo e o repertório: Performance e memória cultural nas Américas. Belo Horizonte: Editora UFMG, 2013.

TURNER, Victor W. Do ritual ao teatro: a seriedade humana de brincar. Tradução de: MARKOWITZ, Michele, ROMEIRO, Juliana. Rio de Janeiro: Editora UFRJ, 2015.

VASCONCELLOS, Sonia Tramujas; STORCK, Karine; MOMOLI, Daniel Bruno. Para onde caminha o ensino das Artes Visuais? Revista GEARTE, Porto Alegre, v. 5, n. 02, mai./ago., 2018, p. 245258. Disponível em: http://dx.doi.org/10.22456/2357-9854.83832. Acesso em: 30 jul. 2019.

Notas

1 A fim de localizarmos as discussões empreendidas especificamente neste texto, consideramos os termos "arte", descrito no singular e com letra inicial minúscula, e "artes", no plural e com letra inicial minúscula, para designarem o seu ensino como disciplina do currículo da educação básica, ensino superior e cursos-livres nas diversas linguagens artísticas: Artes Visuais, Dança, Música e Teatro. As grafias "Arte”, com letra inicial maiúscula e no singular, e "Artes", com letra inicial maiúscula e no plural, serão atribuídas como expressão ao campo dessa área.

2 De modo geral, os dramas sociais de Victor Turner são desenvolvidos em quatro fases que se dão nas inter-relações socioculturais. São elas: 1. Rupturas. Essa fase é marcada por situações que possam ameaçar a estabilidade da unidade social. 2. Crise. É a expansão da fase anterior e a sua abertura para o público. A fase da crise, quando não solucionada, pode desencadear estados de divisão e rivalidade. 3. Ação Reparadora. Buscam-se formas de lidar e solucionar a crise. 4. Reintegração das normas. Visa à solução e ao reestabelecimento da ordem social. Em outros casos, propende-se à separação. 